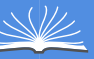

Global Journals In

(2)

\title{
Sensorial Profile and Acceptability of Coffee Blends Submitted to Different Roasting Degrees
}

\author{
By Ana Paula Lelis Rodrigues de Oliveira, Ramon Felipe Neves, \\ Gabriel Henrique Horta de Oliveira \& Magno Vinicius Corrêa de Souza
}

Abstract- Industry of roasted and ground coffee uses Coffea arabica L. (arabica) and Coffeacanephora(robusta), main coffee species, to form blends consumed worldwide. In addition to blends composition, industries also vary the roast degree to attend the consumer market. Being that stated, this work aimed to evaluate the influence of roasting degree and blends composition, using sensorial analysis, over the product acceptability. Arabica and robusta coffee were dehulled, classified, and roasted at Agtrons numbers SCAA\#65 (medium-light) e SCAA\#45 (moderately dark). Afterward, the authors made a preliminary test to select the blends for conventional consumers as a function of robusta coffee percentage. After the selection and determination of adequate proportion $(0,30$, and $60 \% \mathrm{~m} / \mathrm{m})$ of robusta coffee, the researchers invited 49 consumers to perform the tests. The researchers used preliminary tests to indicate that 29 out of the 49 consumers are capable to complete the tests. They performed the sensorial analysis of the blends, signaling grades from 1 to 9 to flavor, aroma, and appearance. Blend composition presented a higher impact over the coffee acceptability than the roast degree, in which coffee with $0 \%$ of robusta coffee, independently of the roast degree, followed by sample with $30 \%$ of robusta coffee roasted at medium light, presented the highest grades.

Keywords: coffea arabica L., coffeacanephora, quality, sensorial analysis, cup test.

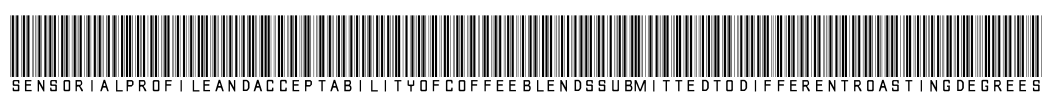

Strictly as per the compliance and regulations of:

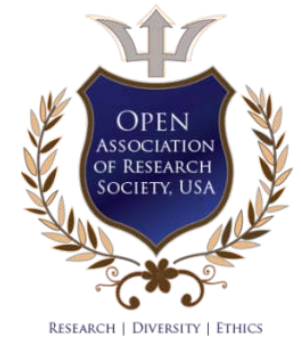

(C) 2020. Ana Paula Lelis Rodrigues de Oliveira, Ramon Felipe Neves, Gabriel Henrique Horta de Oliveira \& Magno Vinicius Corrêa de Souza. This is a research/review paper, distributed under the terms of the Creative Commons Attribution-Noncommercial 3.0 Unported License http://creativecommons.org/licenses/by-nc/3.0/), permitting all non commercial use, distribution, and reproduction in any medium, provided the original work is properly cited. 


\title{
Sensorial Profile and Acceptability of Coffee Blends Submitted to Different Roasting Degrees
}

\author{
Ana Paula Lelis Rodrigues de Oliveira ${ }^{\alpha}$, Ramon Felipe Neves ${ }^{\sigma}$, Gabriel Henrique Horta de Oliveira ${ }^{\rho}$ \\ \& Magno Vinicius Corrêa de Souza ${ }^{\omega}$
}

Abstract- Industry of roasted and ground coffee uses Coffea arabica L. (arabica) and Coffeacane-phora(robusta), main coffee species, to form blends consumed worldwide. In addition to blends composition, industries also vary the roast degree to attend the consumer market. Being that stated, this work aimed to evaluate the influence of roasting degree and blends composition, using sensorial analysis, over the product acceptability. Arabica and robusta coffee were dehulled, classified, and roasted at Agtrons numbers SCAA\#65 (medium-light) e SCAA\#45 (moderately dark). Afterward, the authors made a preliminary test to select the blends for conventional consumers as a function of robusta coffee percentage. After the selection and determination of adequate proportion $(0,30$, and $60 \% \mathrm{~m} / \mathrm{m})$ of robusta coffee, the researchers invited 49 consumers to perform the tests. The researchers used preliminary tests to indicate that 29 out of the 49 consumers are capable to complete the tests. They performed the sensorial analysis of the blends, signaling grades from 1 to 9 to flavor, aroma, and appearance. Blend composition presented a higher impact over the coffee acceptability than the roast degree, in which coffee with $0 \%$ of robusta coffee, independently of the roast degree, followed by sample with $30 \%$ of robusta coffee roasted at medium light, presented the highest grades.

Keywords: coffea arabica L., coffeacanephora, quality, sensorial analysis, cup test.

\section{InTRODUCTION}

$\mathrm{B}$ razil is the foremost producer and exporter of coffee in the world, with 3.06 million tons of harvested coffee and a total of 2.00 million tons of exported coffee in 2017 [1]. Also, Brazil is the second consumer of coffee in the world, being $6.4 \mathrm{~kg}$ of green coffee or $5.1 \mathrm{~kg}$ of roasted coffee per person per year [2]. Coffee belongs to the Coffea genus and possesses two species of greater importance for world commerce, Coffea arabica L. and Coffeacanephora, known as arabica and robusta coffee, respectively.

Arabica coffee represents $76.2 \%$ of Brazilian production, with 2.05 million tons in 2017, while robusta coffee represents 643.200 tons [3]. State of Minas

Author a: Instituto Federal do Sudeste de Minas Gerais - Campus Manhuaçu, Brazil.e-mail: ana.lelis@ifsudestemg.edu.br

Author o: Technician in Coffee Crop.

e-mail: ramonfelipeneves@gmail.com

Author p: Instituto Federal do Sudeste de Minas Gerais - Campus Manhuaçu, Brazil.e-mail: gabriel.oliveira@ifsudestemg.edu.br

Author w: Technician in Coffee Crop.

e-mail:magnocorrea98@outlook.com
Gerais is the leading producer and provides over $50 \%$ of the Brazilian production, mainly with arabica coffee. State of Espírito Santo is the second producer, which cultivates mainly the robusta coffee, with a production estimate of $55.2 \%$ of this specie [3].

Differences among these species vary flowering period, physical and sensorial characteristics of the fruit, and others. Arabica coffee is traditionally more explored commercially, due to the fact of its higher drink acceptance, which provides a higher valorization when compared to the robusta coffee [4]. However, in the past years, robusta coffee increased its market share, due to higher productivity, lower susceptibility of diseases and adaptation at a lower altitude (until $400 \mathrm{~m}$ ) and higher average temperature (between 22 and 26 $\left.{ }^{\circ} \mathrm{C}\right)$ [5]. Moreover, robusta coffee produces a drink with a superiorbody; because of that, it has been used for mixtures (blends) with arabica coffee at the industrialization of roasted and ground coffee [6].

Blends among arabica and robusta coffees may be accomplished to exploit the sensorial potential of both species, combining them to enrich flavor and aroma of the final product, according to the target market [7]. The addition of robusta coffee in the commercial coffee is not commonly accepted by the consumers [8] since it provides a bitter drink, proportional to the amount added of robusta coffee.

In addition to the species, the roasting degree employed during the industrialization process of foodstuff has influence over the sensorial characteristics and, consequently, its market acceptance. For instance, roast of carob pod powder in different conditions and temperatures determines distinct specifications for the product, mainly by those correlated with color, aroma, and flavor [9]. These authors reported that this type of study allows controlling the process, by the food industry, obtaining products with higher acceptance.

The roasting process of the grain has direct influence over the drink quality because during this process occurs modifications and formation of different chemical components that contribute to the final aroma of the drink [10]. The roasting of the green grain forms acid, lactones and other phenolic derived elements, product of the degradation of chlorogenic acids, which impacts at the aroma and flavor of roasted coffee, final acidity, and astringency of the drink [11]. 
Impelled by the roast degree importance over the sensorial characteristics of coffee, Specialty Coffee Association (SCA), former Specialty Coffee Association of America (SCAA), proposed a classification system of the roasted grain by its color, the SCAA-Agtron [12]. In this system, there are five color degrees of the grain, allowing intermediate classifications between very dark, dark, medium, light, and very light. Roast degrees more used commercially, and the ones that most values up flavor and aroma of grain are roast degree medium light and moderately dark [13].

Consumers present a higher worry with aroma, flavor, and color of roasted and ground coffee, appraising its sensorial characteristics, leading the industries to search for an elevated quality of its products using acceptability tests, using sensorial analysis, which depends upon the physical and chemical characteristics of the product [14].

The sensorial analysis permits to diagnose in a scientific and objective way the characteristics that influence the acceptability of food by the consumer, utilizing the senses of an integrated team, trained or not, to identify different organoleptic characteristics of the product. This descriptive analysis evaluates the intensity of the sensorial attributes of several products, allowing a complete description of the differences among samples, orienting modification of the characteristics of the studied product to attend the consumer demands [15].

Thus, considering the economic and industrial importance of the use of blends of arabica and robusta coffee in the formulation of roasted and ground coffee, along with the roast degree, this work had the objective to evaluate the influence of roast and blend composition over the final coffee drink according to the opinion and acceptability of panelists, characterizing the sensorial preferences of the consumer market, using a scientific procedure.

\section{il. Materials and Methods}

\section{a) Raw material}

Coffea arabica L. (arabica coffee) was acquired directly from alocal producer at Manhuaçu city, Brazil, and Coffeacanephora (robusta coffee) was purchased directly from a local producer at Alegre city, Brazil. Later, the researchers transported the grain to the sensorial analysis laboratory located at IF Sudeste MG - Campus Manhuaçu. Afterward, coffee was dehulled.

Intrinsic (imperfections of the own grain) defects such as black, green, sour, broken, and others and extrinsic defects(presence of strange fractions) such as hulls, twigs, and stones, were removed before subsequent procedures. Later, we sent the samples to the roasting process.

\section{b) Roasting process}

The researchers subjected the coffee beans to the roasting process after sorting. We used a 300-g rawcoffee capacity pre-heated, liquefied petroleum gas (LPG) direct roaster with a rotary cylinder operated at 45 rpm to roast the coffee. The degree of roasting of each coffee roast was determined by a trained professional by monitoring the sample color and comparing it with the Agtron/Specialty Coffee Association (SCA) standard roast number. We used two roasting degrees: mediumlight (ML) and moderately dark (MD), corresponding to Agtron numbers of SCAA\#65 and SCAA\#45, respectively (Figure 1).

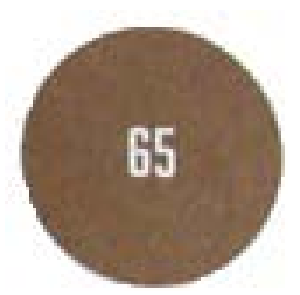

SCAA \#65 - Medium Light

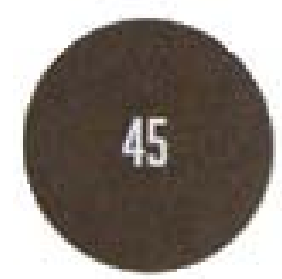

SCAA \#45 - Moderately Dark

Figure 1: Roasting degrees employed: medium-light (A) and moderately dark (B) [16] 


\section{c) Milling process}

Following the roasting process, we processed the coffee beans in a Mahlkönig mill at the medium particle sizes $(0.84 \mathrm{~mm})$.

d) Consumers selection

The researchers used triangle tests to select the appropriate consumers for the sensory evaluation. Consumersfrom Manhuaçu city, from different genders and ages between 16 and 70 years old, were chosen randomly. The consumers gave their consent before they participated in the study.

Consumers filled the Written Informed Consent Form, which explains the objective of the research, with respective name, age, and gender. The model of filing cards for evaluation is shown in Table 1, according to the proposed methodology [18], described below.

Table 1: Filling card model to apply the triangular test

\begin{tabular}{l}
\hline Name: \\
\hline Please, test the sampled codified, from the left to the right. Two samples are equal, and one is different. Identify, with an \\
X, the description that represents the different sample. \\
Please, taste the samples codified from the left to the right.
\end{tabular}

$\begin{array}{lrrr} & \text { Test 1:1.11.21.3 } & \\ \text { Test 2: } & 2.1 & 2.2 & 2.3 \\ \text { Test 3: } & 3.1 & 3.2 & 3.3\end{array}$

Comments:

Six triangle tests were made, separated in two stages, each one with three tests. The first stage (Species) aimed to evaluate if the consumer could identify differences among arabica and robusta coffee. Samples at this stage were $100 \%$ arabica coffee, and $100 \%$ robusta coffee (one different and two equals), and the consumer should indicate which sample was the different one. At the second stage (Roast degree), the objective was to identify which consumers were capable of differentiating samples due to different roasting degrees. Samples at this stage were 100\% arabica coffee, roasted at medium-light, and moderately dark. Again, the consumer should indicate which sample was the different one.

The researchers discarded the consumers that presented success rate below $45 \%$; success rate higher than $70 \%$, the consumer was automatically accepted; between 45 and $70 \%$ of success rate, the test session was continued until we made a final decision regarding the consumer.

\section{e) Sample preparation}

The investigators made different blends among arabica and robusta coffee $(0,30$, and $60 \%$ of robusta coffee) after roasting and the previous grinding of arabica and robusta coffee. We prepared the samples (Table 2) in the proportion of $100 \mathrm{~g}$ of coffee powder and $1.0 \mathrm{~L}$ of mineral water. The drink was extracted according to adapted methodology [17], using filter paper $\mathrm{n}^{\circ} 105$. Samples were served to consumers, individually, in disposable cups.

Table 2: Description of samples submitted to sensorial analysis

\begin{tabular}{ccc}
\hline Sample & Robusta coffee $(\% \mathrm{~m} / \mathrm{m})$ & Roast degree \\
\hline IF 21 & 0 & Medium-Light \\
IF 22 & 30 & Medium-Light \\
IF 23 & 60 & Medium-Light \\
IF 24 & 0 & Moderately Dark \\
IF 25 & 30 & Moderately Dark \\
IF 26 & 60 & Moderately Dark \\
\hline
\end{tabular}

We do not determine the amount of sugar or sweetener at this stage, varying between one and three coffee spoons of sugar. One sugar spoon is equivalent to five drops of sweetener, according to the manufacturer.

\section{f) Sensory analysis}

Quality parameters to be evaluated depends upon consumer opinion [19]. The same authors indicate that the relevant quality characteristics of this public are: flavor, aroma, and appearance, with respective weights of $1.0,0.9$, and 0.7 . To define the required attributes of the product, tests should be quantitative and measurable. The current research used grades between 1.0 and 9.0 for each parameter previously described (flavor, aroma, and appearance). The selected consumers gave these grades, and the final score was calculated using rankings and their respective weights (Table 3). 
Table 3: Qualitative and quantitative parameters for coffee evaluation [19].

\begin{tabular}{ccc}
\hline Quality characteristic (CQ) & Importance (weight) & Grade \\
\hline Flavor & 1.0 & $1-9$ \\
Aroma & 0.9 & $1-9$ \\
Appearance & 0.7 & $1-9$ \\
\hline
\end{tabular}

Each consumer graded six coffee samples, in which a random order of the served samples across

acceptability card (Table 4), to avoid that the testing consumers was established at the individual evaluation

sequel affects the results.

Table 4: Model of acceptability card

\begin{tabular}{|c|c|c|c|}
\hline \multicolumn{4}{|c|}{ Acceptability test } \\
\hline \multicolumn{1}{|c|}{ Name: } & Age: & Gender: (F) (M) & Date: \\
\hline $\begin{array}{l}\text { Please, evaluate the sample using grades between 1 (disliked extremely) and 9 (liked extremely) to describe how much you } \\
\text { liked or disliked the product. Classify to describe, in an integer number, which reflects your judgement. }\end{array}$ \\
\hline \multirow{2}{*}{ Sample code } & \multicolumn{3}{|c|}{ Grades } \\
\cline { 2 - 4 } & Flavor & Aroma & Appearance \\
\hline
\end{tabular}

Along with the served sample, the consumer received a glass of water in environmental temperature to rinse the mouth between evaluations; also, they have received sugar and sweetener to be used as their preference.

\section{ili. Results and Discussion}

a) Consumers selection

After triangular tests for the consumer's selection, results can be seen in Figure 2, which provides the number of consumers able to distinguish between coffee species (arabica from robusta), differentiate between roast degree (medium-light from moderately dark roasts) and the number of consumers able to differentiate coffee samples in general (coffee specie and roast level combined).

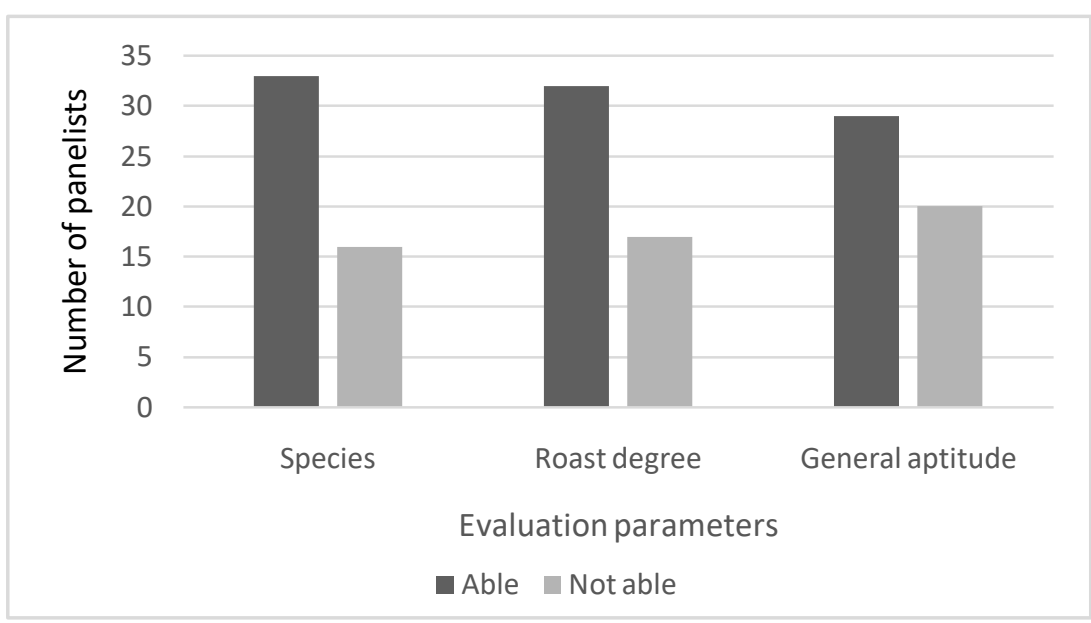

Figure 2: Aptitude evaluation of the consumers as a function of the differentiation ability among coffee samples of different species and roast degrees

According to Figure 2, it is possible to identify that, after the triangular test of the 49 consumers, 33 were considered able regarding the species; in other words, 33 consumers were capable of identifying differences between arabica and robusta coffee. Similarly, 32 consumers among 49 could detect differences regarding roast degree; in other words, 32 consumers can differentiate coffee samples between medium light and moderately dark roasting degrees. In general, according to the classification criteria proposed, 29 consumers were considered able to perform the sensorial analysis, which represents $59.18 \%$ of the consumers (Figure 2).

b) Acceptability test

Figure 3 presents the average grades for each sample, considering the evaluation of the 29 consumers regarding flavor, aroma, and appearance of the different coffee samples (blend composition and roast degree). 


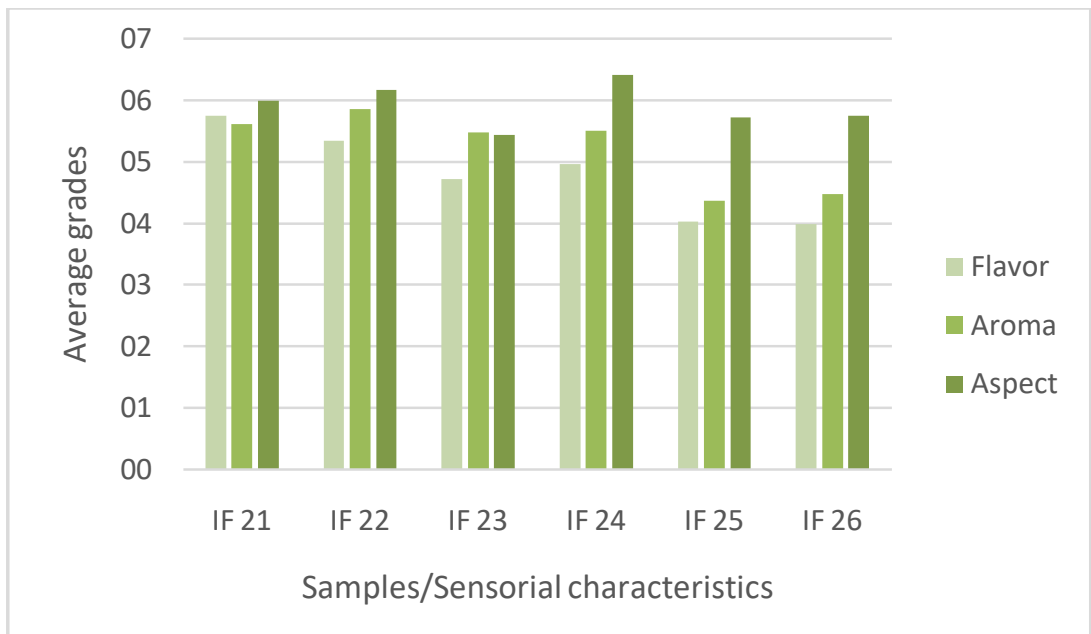

Figure 3: Average grades conceded by the consumers to the coffee samples as a function of sensorial characteristics.

According to Figure 3 samples, IF21 and IF22 presented higher acceptability regarding flavor and aroma. We expected these results because there is a preference by the coffee market for arabica coffee and lighter roast decreases the bitterness. We can explain the same trend for the aroma parameter. However, consumers group preferred coffee drink with darker roasts [20]. We correlated this difference with the regional culture of consumption at Manhuaçu city, which is a region of production of recognized quality coffee. It is established that coffee with higher quality has flavor and aroma parameters pronounced at lighter roasting degrees, and this trend is shared by the selected consumers, even when the selection was random.
Nonetheless, according to Figure 3, sample IF24 presented higher grades of appearance. This result can be explained by the absence of robusta coffee and by the roasting degree. The Brazilian market prefers coffee with darker roasts due to an increase in grinding efficiency, among other factors. Coffee roasted in darker degrees has higher acceptance in four parameters evaluated by a larger group of consumers [20]. 3.3. Sensory analysis

Figure 4 presents the influence of the typical grade as a function of consumer's preference.

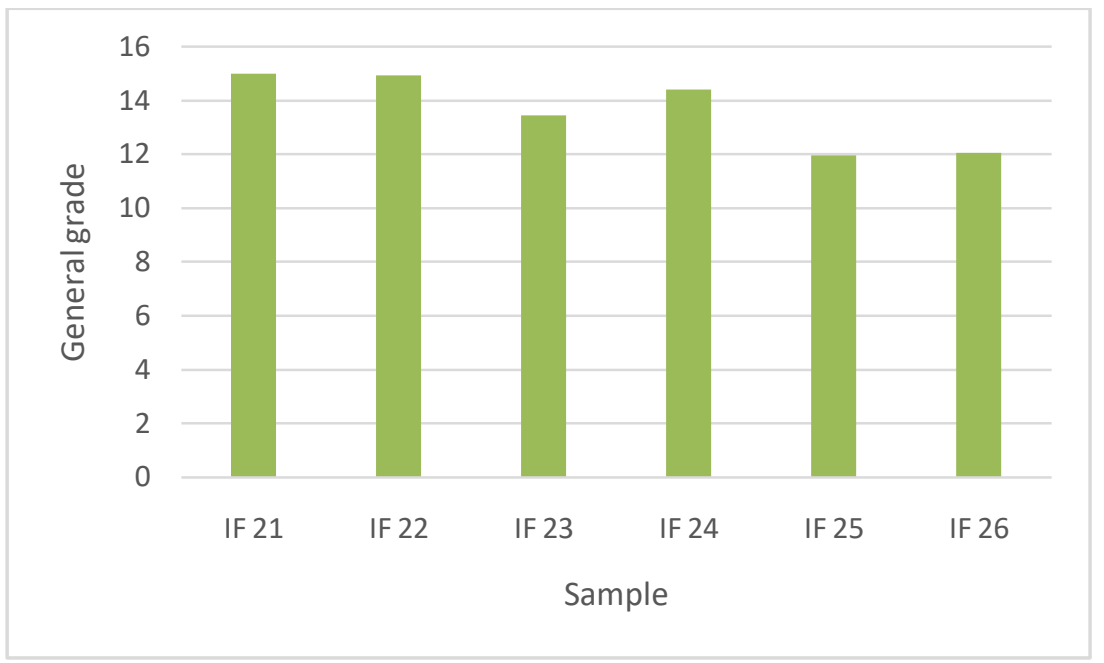

Figure 4: General grades of coffee samples as a function of sensorial characteristics, by its determined weight.

We can observe, in Figure 4, that samples IF21, IF 22, and IF24 were the samples with the highest grades. This trend suggests that robusta coffee is accepted by the market when we roasted it in a medium light degree (IF22). We did not expect this observation, since robusta coffee is related to lower drink quality, among consumers. This trend is more relevant when the demand of the local market (Manhuaçu city) is of coffees of higher quality. Lastly, we noticed a preference for arabica coffee, since that samples that didn't add 
robusta coffee (IF21 and IF24), independently of the roast degree, presented superior grades, among the samples studied (Figure 4).

\section{Conclusions}

Blend composition presented a higher impact over the coffee acceptability than the roast degree, in which greatest grades were indicated by coffee with $0 \%$ of robusta coffee, independently of the roast degree, followed by sample with $30 \%$ of robusta coffee roasted at medium light.

Among the sensorial characteristics evaluated, the addition of robusta coffee affected mostly the flavor.

Funding: This research was funded by Fundação de Amparo à Pesquisa do Estado de Minas Gerais (FAPEMIG) andthe Conselho Nacional de Desenvolvimento Científico e Tecnológico (CNPq) for scholarshipsand financial support.

Conflicts of Interest: The authors declare no conflict of interest. The founding sponsors had no role in the design of the study; in the collection, analyses, or interpretation of data; in the writing of the manuscript, and in the decision to publish the results.

\section{References Références Referencias}

1. OIC - Organização Internacional do Café. Dados históricos. 2017. Available online: http://www.ico.org $/$ pt/new_historical_p.asp?section=Estat\%EDstica. (accessed on 11 of october of 2018).

2. $A B I C$ - Associação Brasileira da Indústria de Café. Indicadores da Indústria de Café no Brasil. 2017. Available online: http://abic.com.br/estatisticas/ indicadores-da-industria/indicadores-da-industriade-cafe-2017/. (accessed on 11 of october of 2018).

3. CONAB - Companhia de Nacional de Abastecimento. Acompanhamento de safra brasileira: Café. 2017. Available online: https://www.conab.gov.br/ component/k2/item/download/16106_945205b3373 e7ca8e09270a79fad36e9. (accessed on 11 of octoberof 2018).

4. Cheng, B.; Furtado, A.; Smyth, H.E.; Henry, R.J. Influence of genotype and environment on coffee quality. Trends in Food Science \& Technology 2016, 57, 20-30, 10.1016/j.tifs.2016.09.003.

5. Paterson, R.R.M.; Lima, N.; Taniwaki, M.H. Coffee, mycotoxins and climate change. Food Research International, 2014, 61, 1-15, 10.1016/j.foodres. 2014.03.037.

6. Illy, A.; Viani, R. Espresso Coffee: The chemistry of quality, 2nd ed.; Academic press: San Diego, 1996; 253p. ISBN 9780123703712.

7. Ribeiro, J.L. (Universidade Federal do Rio Grande do Sul, Porto Alegre, RS, Brazil); Caten, C.T. (Universidade Federal do Rio Grande do Sul, Porto Alegre, RS, Brazil).Personal communication, 2014.
8. Pacetti, D.; Boselli, E.; Balzano, M.; Frega, N.G. Authentication of Italian Espresso coffee blends through the GC peak ratio between kahweol and 16O-methylcafestol. Food Chemistry2012, 135, 15691574, 10.1016/j.foodchem.2012.06.007.

9. Boublenza, I.;Lazouni, H.A.;Ghaffari, L.;Ruiz, K.;Fabiano-Tixier, A.;Chemat, F. Influence of Roasting on Sensory, Antioxidant, Aromas, and Physicochemical Properties of Carob Pod Powder (Ceratonia siliqua L.). Journal of Food Quality2017, 1-10, 10.1155/2017/4193672.

10. Kim, S-Y; Ko, J-A; Kang, B-S; Park, H-J. Prediction of key aroma development in coffees roasted to different degrees by colorimetric sensor array. Food Chemistry2018, 240, 808-816, 10.1016/j.foodchem. 2017.07.139.

11. Lópes-Galilea, I.; Penã, M.P.; Cid, C.I. Correlation of selected constituents with the total antioxidant capacity of coffee beverages: Influence of the brewing procedure. Journal of Agricultural and food Chemistry2007, 55, 6110-6117, 10.1021/jf070779x.

12. SCAA - Speciality Coffee Association of America. SCAA Protocols. 2015. Available online: http:// www.scaa. org/?page $=$ resources $\& d=$ green-coffeeprotocols (accessed on 05 of june of 2016).

13. Vargas-Elias, G.A. Avaliação das propriedades físicas e qualidade do café em diferentes condições de torrefação. Dissertation, Master in Agricultura Engineering, Universidade Federal de Viçosa, Brazil, 2011.

14. Oliveira, A.P.L.R.; Corrêa, P.C.; Reis, E.L.; Oliveira, G.H.H. Comparative Study of the Physical and Chemical Characteristics of Coffee and Sensorial Analysis by Principal Components. Food Analytical Methods2015, 8, 1303-1314, 10.1007/s12161-0140007-4.

15. Larmond, E. Laboratory methods for sensory evaluation of food. Food Research Institute/Canada Department of Agriculture: Ottawa, 1977; 73 p. ISBN 9780662012719.

16. Corrêa, P.C.; Oliveira, G.H.H.; Oliveira, A.P.L.R.; Vargas-Elías, G.A.; Santos, F.L.; Baptestini, F.M. Preservation of roasted and ground coffee during storage Part 1: Moisture content and repose angle. Revista Brasileira de Engenharia Agrícola e Ambiental2016, 20, 581-587, 10.1590/1807-1929/ agriambi.v20n6p581-587.

17. Silva, M.C.;Castro, H.A.O.;Farnezi, M.M.M.;Pinto, N.A.V.D.;Silva, E.B. Caracterização química e sensorial de cafés da chapada de Minas, visando determinar a qualidade final do café de alguns municípios produtores. Ciência e agrotecnologia 2009, 33, 1782-1787, 10.1590/S1413-70542 009000700014.

18. Jordão, F.G. Perfil sensorial e aceitabilidade de suco de laranja integral pasteurizado e suco de 
laranja reconstituído. Dissertation, Master in Sciences, Universidade de São Paulo, Brazil, 2005.

19. Passos, M.L.S; Pereira, L.L.; Carvalho, D. Caten, C.S. Avaliação de diferentes tipos de cafés, com consumidores não treinados a partir do projeto de experimentos: doe - design ofexperiments. In ProceedingoftheXXXV Encontro Nacional de Engenharia de Produção, Fortaleza, Ceará, Brazil, 2015; p. 1-15.

20. Monteiro, M.A.M;Minim, V.P.R;Silva, A.F.;Chaves, J.B.P.I. Influência da torra sobre a aceitação da bebida café. Revista Ceres2010, 57, 145-150, 10.1590/S0034-737X2010000200002. 